\title{
Functional Status and Associated Factors in Patients with Colon Cancer Receiving Chemotherapy
}

\author{
Belgüzar Kara, ${ }^{1, *}$ and Gamze Kaya ${ }^{2}$ \\ ${ }^{1}$ Department of Internal Medicine Nursing, Faculty of Health Sciences, Yüksek İhtisas University, Ankara, Turkey \\ ${ }^{2}$ Department of Oncology, Gulhane Education and Research Hospital, Ankara, Turkey \\ "Corresponding author: Belgüzar Kara, Department of Internal Medicine Nursing, Faculty of Health Sciences, Yüksek İhtisas University, Ankara, Turkey. E-mail: \\ sb.kara@mynet.com \\ Received 2017 April 18; Accepted 2017 August 19.
}

\begin{abstract}
Background: Patients with colon cancer are at risk of developing functional impairment. However, studies on functional status in this population are limited.

Objectives: The aim of this pilot study was to evaluate the functional status in patients with colon cancer and determine its association with sociodemographic and disease-related characteristics and perceived family support.

Methods: This cross-sectional study included 30 patients (53.3\% males) with colon cancer who were followed up by an oncology outpatient clinic in a military hospital in Turkey. Data were collected using a personal data form, the Functional Living Index-Cancer (FLIC), and the Cancer Patient Social Support Scale.

Results: The total mean FLIC score of the patients was $112.9 \pm 22.4$. Female gender and lower levels of family support were associated with poorer functional status $(\mathrm{P}<0.05)$.

Conclusions: The functional status of the patients was higher than the moderate level. A greater understanding of factors associated with functional status in patients with colon cancer could provide appropriate interventions to support functional performance and improve health outcomes.
\end{abstract}

Keywords: Colon Cancer, Family Support, Functional Status

\section{Background}

Colon cancer is one of the most important causes of cancer-related morbidity and mortality worldwide. Advanced age, male gender, family history, and lifestyle factors increase the risk of colon cancer. More than half of the colon cancer cases are diagnosed in patients older than 70 years $(1,2)$. According to Moth et al. (1), "decision-making about treatment with chemotherapy for older adults may be complicated by age-related physiological changes, impaired functional status, limited social support, concerns regarding the occurrence of and ability to tolerate treatment toxicity, and the presence of comorbidities" (p. 1321)". Patients with colon cancer are at risk of developing functional impairment $(3,4)$. However, a limited number of studies with inconsistent results have assessed the factors associated with functional status in this population. Therefore, the aim of this pilot study was to evaluate the functional status in patients with colon cancer and determine its association with sociodemographic and disease-related characteristics and perceived family support.

\section{Methods}

A cross-sectional study was conducted between February and June 2015. A convenience sample of consecutive patients with colon cancer was recruited from an oncology outpatient clinic in a military hospital in Turkey. Inclusion criteria were age of 18 years or older, colon cancer diagnosis for at least one month, having received at least one chemotherapy cycle, being aware of diagnosis, ability to communicate in Turkish, and willingness to participate in the study. Exclusion criteria were cognitive impairment, history of major psychiatric disorder, the presence of substantial physical disability, and unstable clinical status. 30 patients (53.3\% males) with colon cancer were enrolled in this study. The hospital ethical committee approved the study, and written informed consent was obtained from all the participants enrolled in this study.

Data were collected through face-to-face structured interviews and medical records review. In this study, three data collection tools were used: a personal data form, the Functional Living Index-Cancer (FLIC) (5), and the Cancer Patient Social Support Scale (CPSS) (6).

The Turkish version of the FLIC (5) was used to measure functional status. The 22 -item scale is rated on a 7 - 
point Likert-type scale, and it is divided into five subscales: physical functioning (9 items), psychological functioning (6 items), current well-being ( 3 items), social functioning ( 2 items), and gastrointestinal symptoms ( 2 items). The total score ranges from 22 to 154, with higher scores indicating higher levels of functional status. Cronbach's alpha coefficient was 0.80 for the total scale, and it ranged from 0.60 to 0.83 for the subscales (5).

The Turkish version of the CPSS (6) was used to assess social support from family. The 35 -item scale is rated on a 5-point Likert-type scale. It is grouped into three subscales: trust support (13 items), emotional support (12 items), and information support (10 items). Higher scores on the CPSS indicate higher levels of perceived social support from family. Cronbach's alpha was 0.92 for the total scale, and it ranged from 0.87 to 0.88 for the subscales (6).

Descriptive statistics, Mann-Whitney U test, and Spearman's correlation coefficient were used for the analysis of data. The level of significance was set at 0.05 for all the tests.

\section{Results}

Table 1 presents the sociodemographic characteristics of the participants. The mean age of the patients was 60.0 \pm 11.8 years, and the range of ages was wide (range $=22-75$ ). Twenty eight patients (93.3\%) were 40-years-old or older. The median duration of disease was 12 months (range = 1 - 84). Half of the patients (50.0\%) were graduated from high school or universities (22.9\%). Most of the patients were married (70.0\%), not working (93.3\%), had moderate or adequate income (66.7\%), and were living with family members (86.7\%). The majority of the patients (90.0\%) had metastases, and underwent surgical intervention for colon cancer (96.7\%). Eleven patients (36.7\%) had also comorbidity.

As shown in Table 2, the total mean FLIC score of the patients was $112.9 \pm 22.4$, and the total mean CPSS score was $147.4 \pm 12.7$. The total mean FLIC scores were lower in females than males $(z=-2.16, P=0.031)$. There was no significant difference in age by gender $(\mathrm{z}=-0.52, \mathrm{P}=0.603)$. The total FLIC scores were also positively correlated with the total CPSS score $(r=0.55, P=0.002)$, as well as with the emotional support $(\mathrm{r}=0.54, \mathrm{P}=0.002)$ and information support subscale scores of the CPSS $(\mathrm{r}=0.56, \mathrm{P}=0.001)$.

\section{Discussion}

The results of this pilot study suggested that the functional status of the patients was higher than the moderate
Table 1. Description of Participants' Characteristics ( $\mathrm{N}=30$ )

\begin{tabular}{|c|c|}
\hline Variables & No. (\%) \\
\hline \multicolumn{2}{|l|}{ Gender } \\
\hline Male & $16(53.3)$ \\
\hline Female & $14(46.7)$ \\
\hline \multicolumn{2}{|l|}{ Marital status } \\
\hline Married & $21(70.0)$ \\
\hline Unmarried & $9(30.0)$ \\
\hline \multicolumn{2}{|l|}{ Education level } \\
\hline High school or greater & $15(50.0)$ \\
\hline Literate/primary school/secondary school & $15(50.0)$ \\
\hline \multicolumn{2}{|l|}{ Employment status } \\
\hline Not working & $28(93.3)$ \\
\hline Working & $2(6.7)$ \\
\hline \multicolumn{2}{|l|}{ Income level } \\
\hline Moderate or adequate & $20(66.7)$ \\
\hline Inadequate & $10(33.3)$ \\
\hline \multicolumn{2}{|l|}{ Living arrangement } \\
\hline Living with family & $26(86.7)$ \\
\hline Living alone & $4(13.3)$ \\
\hline \multicolumn{2}{|l|}{ Caregiver } \\
\hline Present & $24(80.0)$ \\
\hline Absent & $6(20.0)$ \\
\hline
\end{tabular}

Table 2. Mean Scores, Standard Deviations (SDs), and Ranges for the Functional Living Index-Cancer (FLIC), and the Cancer Patient Social Support Scale (CPSS) (N=30)

\begin{tabular}{llcc}
\hline Variables & Mean \pm SD & Range \\
\hline FLIC & & & \\
\hline & Physical functioning & $43.7 \pm 11.5$ & $23-63$ \\
& Psychological functioning & $32.9 \pm 5.5$ & $24-42$ \\
& Current well-being & $15.0 \pm 3.8$ & $6-21$ \\
\hline & Social functioning & $11.1 \pm 2.5$ & $6-14$ \\
& Gastrointestinal symptoms & $10.2 \pm 3.8$ & $2-14$ \\
\hline & Total scale & $112.9 \pm 22.4$ & $64-146$ \\
\hline CPSS & & & \\
\hline & Trust support & $61.2 \pm 4.8$ & $50-65$ \\
\hline & Emotional support & $52.5 \pm 5.8$ & $35-60$ \\
\hline & Information support & $33.7 \pm 5.4$ & $23-46$ \\
\hline & Total scale & $147.4 \pm 12.7$ & $113-171$ \\
\hline
\end{tabular}

level. In a study in the United States, Phipps et al. (7) indicated that quality of life was good in long-term colon can- 
cer survivors. However, in a retrospective cohort study in the United States, Finlayson et al. (8) showed that mortality and functional decline are prevalent after colon cancer surgery in elderly nursing home residents.

Another notable result of our pilot study was that gender was associated with functional status of patients with colon cancer. The results of other studies are conflicting with regard to the influence of gender on functional status. Similarly, Phipps et al. (7) found that females reported greater role limitations caused by physical problems and more pain than males. Finlayson et al. (8) also showed that gender was not associated with functional decline in patients aged 65 or older who underwent surgery for colon cancer.

We found that family support in patients with colon cancer was higher than the moderate level. In this study, family support was associated with functional status. According to Hubbard (9), one of the factors affecting tolerance of treatment is the perceived social support level of the patients with colon cancer. Adequate family support can therefore be very important in helping patients solve their problems and it can facilitate their functional improvement and well-being.

This pilot study had some limitations such as its crosssectional design, the small sample size, and convenience sampling of patients with colon cancer. Therefore, the results cannot be generalized to other Turkish patients with colon cancer. A greater understanding of factors associated with functional status in patients with colon cancer could provide appropriate interventions to support functional performance and improve health outcomes.

\section{Acknowledgments}

The authors thank all the patients who participated in this study.

\section{Footnote}

Conflict of Interest: The authors declare that there are no conflicts of interest.

\section{References}

1. Moth EB, Vardy J, Blinman P. Decision-making in geriatric oncology: systemic treatment considerations for older adults with colon cancer. Expert Rev Gastroenterol Hepatol. 2016;10(12):1321-40. doi: 10.1080/17474124.2016.1244003. [PubMed: 27718755].

2. Kolligs FT. Diagnostics and Epidemiology of Colorectal Cancer. Visc Med. 2016;32(3):158-64. doi: 10.1159/000446488. [PubMed: 27493942].

3. Lamprecht J, Thyrolf A, Mau W. Health-related quality of life in rehabilitants with different cancer entities. Eur J Cancer Care (Engl). 2016 doi: 10.1111/ecc.12554. [PubMed: 27482937].

4. van Erning FN, Janssen-Heijnen ML, Wegdam JA, Slooter GD, Wijsman $\mathrm{JH}$, Vreugenhil A, et al. The Course of Neuropathic Symptoms in Relation to Adjuvant Chemotherapy Among Elderly Patients With Stage III Colon Cancer: A Longitudinal Study. Clin Colorectal Cancer. 2016 doi: 10.1016/j.clcc.2016.09.002. [PubMed: 27756521].

5. Bektas HA, Akdemir N. Reliability and validity of the Functional Living Index-Cancer in Turkish cancer patients. Cancer Nurs. 2008;31(1):E1-7. doi: 10.1097/01.NCC.0000305684.51884.1f. [PubMed: 18176121].

6. Eylen B. A study of reliability, validity and factorial structure of the Cancer Patient Social Support Scale [In Turkish].Journal of Uludag University Faculty of Education. 2002;15(1):109-17.

7. Phipps E, Braitman LE, Stites S, Leighton JC. Quality of life and symptom attribution in long-term colon cancer survivors. J Eval Clin Pract. 2008;14(2):254-8. doi: 10.1111/j.1365-2753.2007.00842.x. [PubMed: 18284521].

8. Finlayson E, Zhao S, Boscardin WJ, Fries BE, Landefeld CS, Dudley RA. Functional status after colon cancer surgery in elderly nursing home residents. J Am Geriatr Soc. 2012;60(5):967-73. doi: 10.1111/j.15325415.2012.03915.x. [PubMed: 22428583].

9. Hubbard JM. Management of Colorectal Cancer in Older Adults. Clin Geriatr Med. 2016;32(1):97-111. doi: 10.1016/j.cger.2015.08.002. [PubMed: 26614863]. 